Научная статья

УДК 101.1: 316

DOI: 10.18101/1994-0866-2021-3-67-72

\title{
СОЦИАЛЬНАЯ РЕАЛЬНОСТЬ: НОРМАТИВНО-ИНТЕРПРЕТАТИВНЫЙ ПОДХОД
}

\author{
(C) Пронер Нина Сергеевна \\ кандидат философских наук, доцент, \\ Новосибирский государственный технический университет \\ Россия, 630073, г. Новосибирск, пр. К. Маркса, 20 \\ kafedra@ngs.ru \\ (C) Богатырева Оксана Александровна \\ старший преподаватель, \\ Новосибирский государственный технический университет \\ Россия, 630073, г. Новосибирск, пр. К. Маркса, 20 \\ bogatirevaoksana@mail.ru
}

\begin{abstract}
Аннотация. В настоящей статье авторы предприняли попытку рассмотреть подходы и стратегии изучения социальной реальности. Актуальность данной статьи связана с существующими социальными трансформациями современного общества, являющимися следствиями информатизации всех социальных сфер. В качестве методологической базы исследования использованы нормативный и интерпретативный подходы, а также общенаучный принцип дополнительности. Сетевая теория трактуется как метатеория, позволяющая объяснить всю социальную реальность. Итогом работы является вывод о том, что рассматривать социальную реальность необходимо как целостный, универсальный, непрерывно-прерывистый процесс. Знания, один из элементов данного процесса, приводят не только к увеличению сетевой структуры, но и к ее интерпретации и переструктурированию. Наиболее адекватным для изучения социальной реальности является единый нормативноинтерпретативный подход.

Ключевые слова: социальная реальность, нормативно-интерпретативный подход, принцип дополнительности, сетевая теория, знания, информация, ценности, нормы, смыслы, язык.
\end{abstract}

Благодарности. Работа выполнена при поддержке РФФИ. Проект № 19-013-00208.

\section{Для цитирования}

Пронер Н. С., Богатырева О. А. Социальная реальность: нормативноинтерпретативный подход // Вестник Бурятского государственного университета. Философия. 2021. Вып. 3. С. 67-72.

Существующая специфика современных информационно-технологических социальных изменений, а именно ускорение темпов развития личности и общества, приводит к тому, что оно осуществляется в условиях бессистемной интенсификации информационных потоков. При этом человек признается движущей силой этого процесса. В связи с этим в современной науке активно дискутируются вопросы, касающиеся идентификации и принципов организации общества. Одна часть исследо- 
вателей считает, что существующие для обозначения современного общества понятия «общество знания» и «информационное общество» не стоит разграничивать, поскольку общество знания является этапом в развитии общества. Другая часть отстаивает идею о том, что общество знания (knowledge-based society) представляет собой современный тип организации общества, в котором в развитии всех сфер общества основопологающее значение придается знанию, а не информации, как в информационном обществе [10, с. 22]. Таким образом, современные дискуссии, связанные с вопросами выявления сущностных характеристик, принципов и особенностей организации общества, далеки от своего завершения. Но, несмотря на существование самых разных точек зрения, стоит отметить, что современная социальногуманитарная мысль максимально широко охватывает проблемы, связанные с понятиями «информационное общество», «информация», «знания». При этом «знания» и «информация» могут рассматриваться как синонимичные понятия, поскольку под информацией понимается прежде всего совокупность осмысленных и упорядоченных данных о реальности. В данном контексте все же стоит развести эти понятия, поскольку знания включают в себя ценности, опыт, контекстуальную информацию, являющиеся основой для создания оценки новой информации и опыта.

При этом общество знаний начинают оценивать как новый социальный идеал, как некий образец совершенства, являющийся результатом социокультурной динамики. Кроме того, сами знания рассматриваются в качестве основного продукта познания реальности во всем ее многообразии, а нормы - в качестве основного продукта человеческой практики. Гносеология признает существование объективной реальности независимо от человеческого сознания, а также способность познать и оценить ее. Отдельно стоит обратить внимание на идеи П. В. Копнина, который уже почти пятьдесят лет назад утверждал: «Знание, будучи языковой системой, образует свой своеобразный мир, имеющий определенную структуру, включающую в себя связь между элементами, ее образующими, по известным правилам»... «Бесплодно, вырвав какой-нибудь элемент этой системы, пытаться решить вопрос об изоморфизме его структуры и структуры вещей и процессов. Он приобретает смысл и значение только в системе, т. е. в той форме человеческой деятельности, посредством которой целесообразно практически преобразуются вещи и процессы объективной реальности» [4, с. 192].

Поскольку познание - это процесс приращения знаний, то можно утверждать, что в любой момент времени фиксируется недостаточность знаний относительно окружающей реальности, что, в свою очередь, приводит к необходимости выстраивания взаимосвязей с уже имеющимися знаниями, т. е. к порождению контекста и концепта, тех элементов, которые можно подвергнуть интерпретации.

Знание о нормативном как общезначимом и неизменном задаётся вполне определенными культурными пределами. Эти пределы допускают возможность нарушения их меры в определенных отношениях и связях. Соответственно мы можем говорить об объективном существовании в культуре плюрализма тех или иных ценностей, заложенных в том или ином знаке. Из веера допустимых значений каждый человек и выбирает то, что значимо конкретно для него. При этом «анормальность» превращается в возможность, если существующие определения реальности конкурентоспособны настолько, что позволяют сделать выбор между ними. 
Ценность при таком подходе можно рассматривать как интерпретацию реальности, в которой субъект выражает свои предпочтения относительно нее. Языковая картина мира становится репрезентантом наших аксиологических установок.

Современные научные теории, концепции и подходы с разных сторон пытаются рассмотреть процессы, связанные с пониманием, отражением и интерпретацией, моделированием реальности. Так, современные лингвистические теории [2], работающие в первую очередь с текстами, предполагают, что понимание возникает как результат восприятия различных типов информации: фактуальной, подтекстовой и концептуальной. Причем с точки зрения содержания можно говорить о том, что та или иная информация является результатом диалектического процесса, в рамках которого происходит борьба между фактуальной и концептуальной информацией. Синергетический подход утверждает, что изменения, происходящие в сознании человека, есть результат того, что в точке бифуркации происходит перелом в понимании реальности, выбор новых параметров восприятия действительности, приводящих к новому состоянию устойчивости, изменение траектории движения. В последние годы весьма востребованными (благодаря развитию информационных технологий) как в социальной философии, так и теоретической социологии становятся сетевые теории, наиболее влиятельными из которых являются концепции М. Кастельса, Б. Уэлмана, Р. Коллинза и др. Социальные отношения последователями сетевой теории ставятся во главу угла, поэтому они объясняют социальные процессы в понятиях «связи», «взаимодействия», «отношения». Результатом этих процессов становится увеличение информационного поля сетевой структуры. Отдельные исследователи [1] настаивают на универсальном характере сетевых процессов.

Знания оказываются важнейшим элементом социальной сети, представляющие собой горизонтальные и многоуровневые системы, но не иерархичные. В данном контексте реальность рассматривается как сеть взаимоотношений, следовательно, описание реальности представляет собой выстраивание взаимосвязанных элементов, при котором отсутствует подчинение высшего и низшего. Конечно, подобный взгляд на знание, как на элемент сети, является непривычным, но он вытекает из сущности и методологии сетевого подхода. Это, в свою очередь, предполагает необходимость формирования самых разных и весьма противоречивых сетей, в которую вплетаются имеющиеся у нас знания, следовательно, нормы (ценности) и смыслы.

Любое сложное явление бытия, в том числе и социальная реальность, не может быть однозначно определено. Для любого определения требуется по крайней мере два взаимоисключающих дополнительных понятия.

Л. Б. Сандакова [8], уточняя содержание общенаучного принципа дополнительности применительно к социогуманитарным исследованиям и возможностям его использования с точки зрения его методологической значимости, утверждает, что принцип дополнительности представляет собой важную составляющую в рамках полипарадигмального и комплексного подходов, позволяющую изучать сложную, динамическую систему языка в его обусловленности мировоззрением и картиной мира. Когда исследователи социальных процессов [6] сталкиваются с необходимостью описаний реальности, дополняющих друг друга, тогда принцип дополнительности становится для них особо значимым. В. Н. Порус отмечает, что «дополняющие друг друга описания определенной реальности, будучи отторгнуты друг от дру- 
га, не только не дают целостного описания, но и могут вступить в противоречие с фактами, если претендуют на целостность, а не включают признание своей принципиальной неполноты. Можно даже сказать, что эти описания образуют сопряженную смысловую пару» [5, с. 111].

Знание порядка существования тех или иных объектов облегчает исследовательские мероприятия, помогает предугадать характер процессов, например, при переходе в качественно другое состояние системы, и многое другое. Человек стремится к идеалу и конструирует сам идеал, а затем видоизменяет и саму реальность.

Фактуальная социальная реальность ни при каких условиях не может быть повторно воспроизведена в первоначальном виде, а может быть выражена только посредством языка и интерпретирована. С. С. Сергеев отмечает в своих исследованиях, что адекватное представление о действительности, таящееся за «...«протокольными историческими фактами», нуждается не только в знании, самом по себе, но и в понимании контекста, в котором они сформированы. А контекст, как известно, образуется как объективными обстоятельствами, так и субъективностью исследователя» [7, c. 106]. Человек сам формируют социальные феномены. Представления о социальном конструировании реальности разрабатывались и изучались на основании разных подходов. Особое место в этих исследованиях занимают философская герменевтика и феноменология.

Герменевтика обращает внимание на методы интерпретации социальной действительности. Окружающая реальность понимается как социальнолингвистическая конструкция, поскольку знание о ней возможно только в языке и посредством языка.

При этом идея о том, что язык является коллективным хранителем информации о мире в целом, об обществе и его характеристиках, обнаруживается как в герменевтических, так и в феноменологических исследованиях. Феноменологи полагают, что сама сущность социальной реальности должна восприниматься как текст, что, в свою очередь, порождает множество интерпретаций этой самой сущности, репрезентируемых в процессе коммуникации, в процессе речевой и языковой деятельности. Язык же определяется способом концептуализации мира [9].

Получая новые знания о мире, человек соотносит ее с уже наличествующей в его сознании. Так рождаются новые смыслы о реальности. При этом, как отмечает Д. И. Гинев, раскрывая место герменевтического реализма среди других подходов философии, существует некая интерпретативная, предналичествующая структура конституирования смысла. Благодаря этой структуре создаются изначальные возможности соединения воспринимающих субъектов и эмпирических объектов. Это специфическая герменевтическая модель конституирования, которая разделялась как в хайдеггеровской, так и гуссерлевской феноменологии.

С точки зрения Д. И. Гинева, «конституирование смысла является процессом непрерывным, тогда как конституирование знания непременно выражается дискретными структурами (утверждениями, гипотезами, концептуальными структурами, моделями, теориями)» [3, с. 32]. Такое понимание приводит нас к попытке использования единого нормативно-интерпретативного подхода.

Нормативный подход к изучению социальной реальности предполагает наличие в ней символов, значений, норм и ценностей, которые принудительно навязываются 
человеку. В процессе социализации партнеры по взаимодействию интерпретируют социальные явления и соотносят их с известными им образцами. Этот процесс носит непрерывный характер.

Интерпретативный подход к исследованию социальной реальности рассматривает интерпретативность как качество, присущее любой культуре, представляющее собой конструирование, моделирование человеком социальной реальности, реализуемое в процессе непрерывной интерпретации.

Таким образом, трансформация общества приводит к изменению представлений о нем и поиску новой методологии исследования. Принцип дополнительностии, его эвристический потенциал, нормативно-интерпретативный подход, сетевая методология позволяют в полной мере рассматривать социальную реальность как целостный непрерывно-прерывистый процесс, в рамках которого можно выделять узлы (акторы) и связи, взаимодействия и отношения. Одними из таких узлов оказываются знания, представляющие собой совокупность ценностей, опыта, информации и смысла, позволяющего его интерпретировать.

Человек не автоматически воспроизводит полученное в процессе социализации знание, а создает свое представление о реальности, как и саму социальную реальность с учетом сложной социальной сети, в которую он включен.

Литература

1. Белокрылова В. А. Сетевые структуры в социально-онтологическом пространстве современного общества // Информационно-образовательные и воспитательные стратегии в современном обществе: национальный и глобальный контекст: материалы международной научной конференции (г. Минск, 12-13 ноября 2009 г.) Минск: Право и экономика, 2010. 762 с. Текст: непосредственный.

2. Гальперин И. Р. Текст как объект лингвистического исследования. Изд. 4-е, стереотипное. Москва: КомКнига, 2006. 144 с. (Лингвистическое наследие XX века.) Текст: непосредственный.

3. Гинев Д. И. Между феноменологией и постаналитической философией: перспектива герменевтического реализма // Epistemology \& Philosophy of Science. 2010. № 4. URL: https://cyberleninka.ru/article/n/mezhdu-fenomenologiey-i-postanaliticheskoy-filosofieyperspektiva-germenevticheskogo-realizma (дата обращения: 18.04.2021). Текст: электронный.

4. Копнин П. В. Диалектика, логика, наука. Москва: Наука, 1973. 463 с. Текст: непосредственный.

5. Порус В. Н. Эпистемология: некоторые тенденции // Вопросы философии. 1997. № 2. С. 93-111. Текст: непосредственный.

6. Ромм М. В. Социальная адаптация личности как объект философского анализа: диссертация на соискание ученой степени доктора философских наук. Томск, 2003. 287 с. Текст: непосредственный.

7. Сергеев С. С. Философские проблемы исторического факта // Омский научный вестник. 2009. № 1(75). С. 105-107. Текст: непосредственный.

8. Сандакова Л. Б. Принцип дополнительности в исследовании связи языка, мировоззрения и картины мира // Сибирский философский журнал. 2019. Т. 17, № 3. С. 66-82. Текст: непосредственный.

9. Шабалин Д. Г., Пурынычева Г. М. Проблема языковых характеристик социальности // Вестник ЧГУ. 2012. № 4. URL: https://cyberleninka.ru/article/n/problemayazykovyh-harakteristik-sotsialnosti (дата обращения: 12.05.2021). Текст: электронный. 
10. Хан А. В. На пути к обществам знаний // Наука в информационном обществе. Санкт-Петербург, 2004. С. 22-26. Текст: непосредственный.

Статья поступила в редакцию 24.06.2021; одобрена после рецензирования 05.07.2021; принята к публикациии 14.09.2021.

\title{
SOCIAL REALITY: A REGULATORY AND INTERPRETATIVE APPROACH
}

\author{
Nina S. Proner \\ Cand. Sci. (Philos.), A/Prof., \\ Novosibirsk State Technical University \\ 20 Karla Marksa Prospect, Novosibirsk 630073, Russia \\ kafedra@ngs.ru
}

Oksana A. Bogatyryova

Senior Lecturer,

Novosibirsk State Technical University

20 Karla Marksa Prospect, Novosibirsk 630073, Russia

bogatirevaoksana@mail.ru

Abstract. In the article, we have attempted to consider approaches and strategies for studying social reality. The relevance of this research is associated with the current social transformations of modern society as a consequence of the computerization of all social spheres. As a methodological basis for the study, we have used regulatory and interpretative approaches, as well as the general scientific principle of complementarity. Network theory is interpreted as a metatheory that explains the entire social reality. As a result of the study, we have concluded that it is necessary to consider social reality as an integral, universal, continuous-discontinuous process. Knowledge as one of the elements of this process not only enlarges the network structure, but also interprets and restructures it. So, a unified regulatory and interpretative approach is the most valid method for studying social reality. Keywords: social reality, regulatory and interpretive approach, complementarity principle, network theory, knowledge, information, values, regulations, meanings, language

\section{For citation}

Proner N. S., Bogatyryova O. A. Social Reality: A Regulatory and Interpretative Approach. Bulletin of Buryat State University. Philosophy. 2021; 3: 67-72 (In Russ.).

Acknowledgments. This work was supported by the Russian Foundation for Basic Research. Project No. 19-013-00208.

The article was submitted 24.06.2021; approved after reviewing 05.07.2021; accepted for publication 14.09.2021. 